\title{
INTERNATIONAL SCIENTIFIC CONFERENCE \\ STRUCTURAL INTEGRITY AND LIFE OF NPP EQUIPMENT (Resource-2012)
}

The International Scientific Conference on Structural Integrity and Life of NPP Equipment (SIL-2012) was held on October 2-5, 2012 in Kiev at the Pisarenko Institute of Problems of Strength of the National Academy of Sciences of Ukraine. The organizers of the Conference were the Pisarenko Institute of Problems of Strength under the auspices of the Scientific Council on the Problem "Mechanics of a Deformable Solid Body" under the Department of Mechanics of the National Academy of Sciences of Ukraine, the National Nuclear Energy Generating Company "Energoatom," the Ministry of Fuel and Energy of Ukraine, the Scientific Coordination and Expert Council on Problems of Life and Safe Operation of Structures, Facilities, and Machines.

The main objective of the Conference was to cover scientific and engineering approaches to the assessment of the structural integrity and life and their use for solving problems both in ensuring the safe operation and in extending the service life of reactor pressure vessels and critical elements of NPP equipment.

More than 170 scientists and experts from research institutes, universities, design-and-planning organizations and industrial enterprises engaged in solving problems on the above topics participated in the Conference.

The Conference program included over 120 paper presentations by authors from such countries as Belarus, Bulgaria, the Czech Republic, Germany, Hungary, Russia, Spain, and Ukraine. The presentations dealt with findings of fundamental and applied investigations on the solution of the following issues:

- limit state criteria for metals under static, dynamic and cyclic loading;

- evaluation of the in-service degradation of material structure and properties;

- methods for taking into account the effect of manufacturing and in-service defects on the ultimate state of materials and structural elements;

- methods for assessing the structural integrity;

- currently available methods assessing the reliability and life of NPP structural components;

- methods for assessing the service life, including the remaining life;

- extension of the useful life.

According to the Program Committee resolution, the presentations made by the Conference participants are published in this issue of journal "Strength of Materials" (No. 4, 2013) and in issues of the collected papers "Reliability and Life of Machinery and Structures" (No. 37, 2013).

The Program Committee believes that the publication of the papers will promote a closer cooperation between scientific teams and all concerned organizations and enterprises in tackling the problems on safe operation, structural integrity, service life and extension of the useful life of reactor pressure vessels and critical elements of NPP equipment and will contribute to further progress in this field of investigations.

V. V. Kharchenko Chairman of the Program Committee Corresponding Member of the National Academy of Sciences of Ukraine

Translated from Problemy Prochnosti, No. 4, pp. 5 - 6, July - August, 2013. Original article submitted October 3, 2012. 